\title{
ATUALIDADE
}

\section{Brasil e Portugal trocam informações e experiências}

A vinda ao Brasil do ministro português da Administração, pletou o circuito de troca de informações iniciado com a visita que o ministro Aluizio Alves fez a Portugal, em julho deste ano. Naquela oportunidade, o ministro brasileiro visitou o Instituto Nacional de Administração de Portugal e pôde sentir a profundidade do trabalho de modernização do serviço público português.

Para o presidente do Instituto Nacional de Administração de Portugal, sua vinda ao Brasil mostrou que foram encontrados alguns pontos convergentes de interesses, "que motivaram o desejo mútuo de uma troca de informaçoes aprofundada, sobre os problemas da formaço, de treinamento de agentes de administração pública c também com a forma de administraçao".

O Instituto Nacional de Administração de Portugal, segundo o seu presidente, João José R. F. da Silva, juntamente com o Ministério da Administração, têm um caminho a percorrer a partir de agora, que é o de colaborar, uma vez que Portugal e Brasil têm o mesmo problema: a administração pública é muito semelhante, e "nesse aspecto, acho que essa colaboração pode ser muito relevante".

Sobre as principais dificuldades que a administração pública portuguesa tem enfrentado, o Professor João José R. F. da Silva afirmou que derivam, em primeiro lugar, de

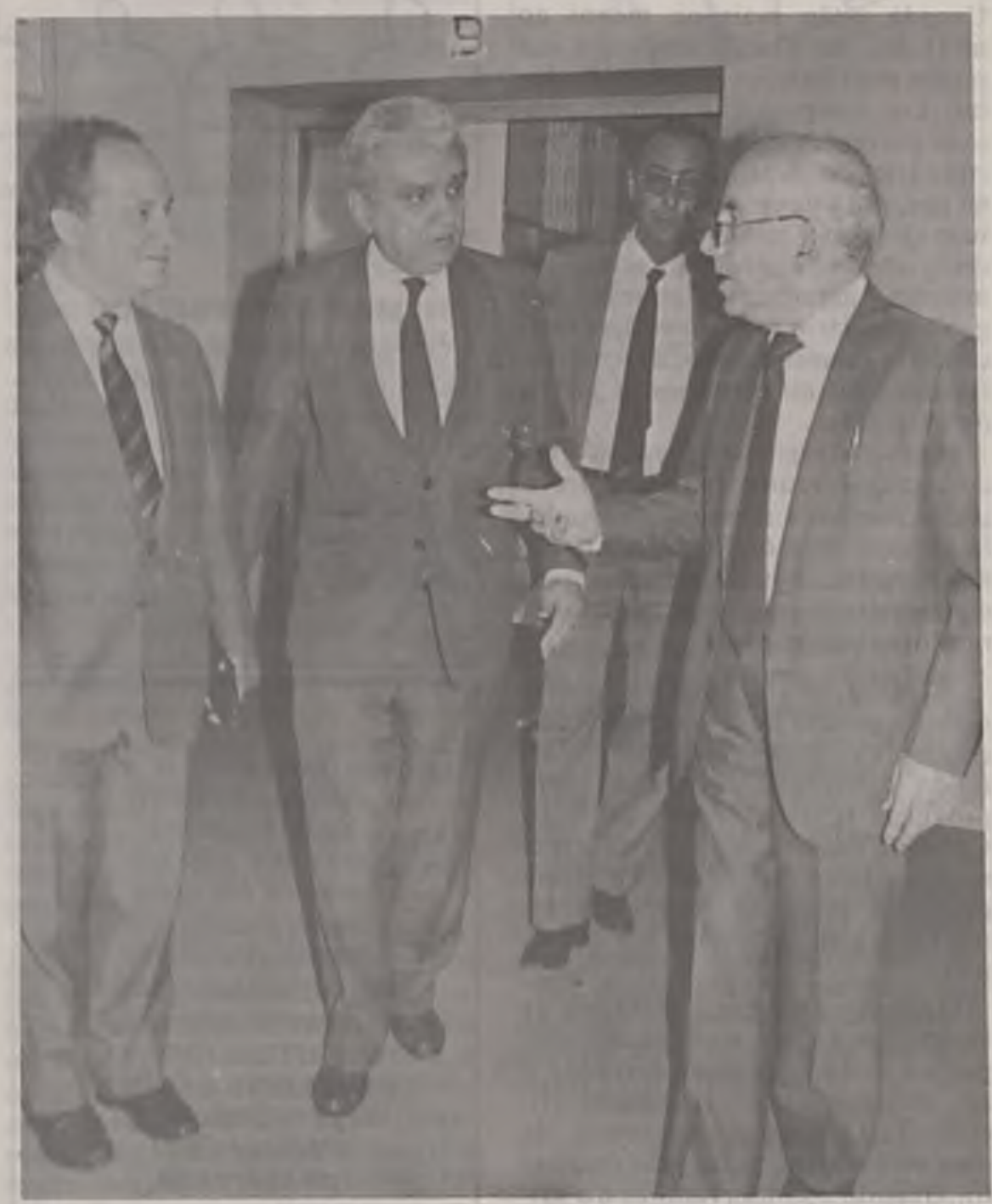

O ministro Aluizio Alves recebeu o seu colega português, Joåo José R. F. da Silva, que visitou inclusive a Funcep 


\section{ATUALIDADE}

uma simetria de situaçóes, em função da iniciativa privada, provocando uma permanência de funcionários no setor público, que não se sentem muito motivados por essa carreira.

Alèm deste problema, destacou três outros que a administração pública de Portugal vem enfrentando: a inibição de carreiras, graves desarmonias salariais e um quadro incompleto para formação e proteção da carreira do funcionário público, "não sendo possivel que se Iransforme tudo do dia para a noite, mas que está certo de que a experiência que se está tendo neste momento será igualmente muito benéfica para Portugal e Brasil, ambos com problemas idênticos".

Comparando a administração pública de hoje com a de Portugal antes da Revolução dos Cravos em 1974, o Professor João Josê R. F. da Silva, disse que, depois deste pcriodo, o número de "retiros" na atual administração quase que triplicou. Observou-se, também, a criação de novas necessidades de vida ou crescimento de profissões determinadas.

Citou como exemplo o surgimento da profíssão de informática, com - aparecimento de necessidades, quanto ao aumento do controle fiscal das despesas públicas, o que acabou provocando distorcóes salariais, já tendo começado alguma competição, inclusive entre os servicos da administração.

- Se for comparar, antes ou depois de 74 , obviamente terei que estabelecer um confronto entre o sistema que estava por assim dizer arrumado, com um sistema que neste momento está desarrumado. Mas terei ainda que comparar com um sistema pouco empenhado, pouco motivado, com um sistema que está fortemente motivado com as novas perspectivas democráticas, de modo que há aspectos negativos e positivos. A motivação hoje em dia, porém, é uma qualidade muito importante.

Explicando a importância da visita do presidente do Instituto Nacional de Administração de Portugal ao Brasil, o ministro da Administração, Aluízio Alves, disse que ela se destacou devido à sua experiência transmitida à Fundação Centro de Formação do Servidor Público e ao próprio Ministério da Administra-

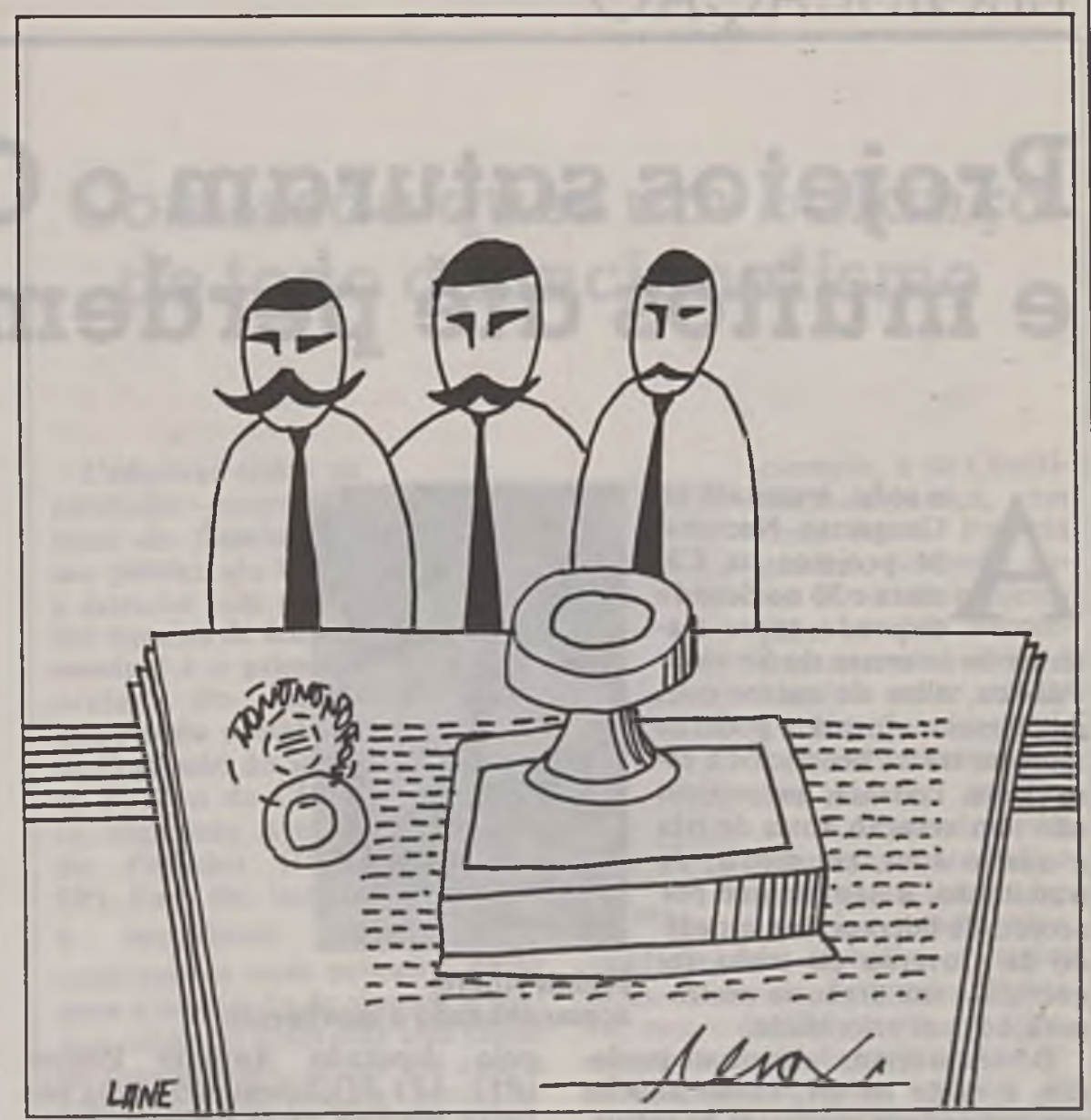

ção, "sobretudo no tocante à organização das carreiras dos servidores públicos de que estamos tratando e ao programa de treinamento que pretendemos implantar para dar melhor qualificação profissional aos funcionários".

O Ministro da Administração lembrou que, no encontro com o

\begin{tabular}{|c|}
\hline O plano de carreira \\
foi um dos temas \\
mais discutidos entre \\
o ministro Aluizio \\
Alves e o presidente \\
do Instituto Nacional \\
de Administracão \\
de Portugal, porque \\
será um dos próximos \\
passos a serem dados \\
no marco da reforma \\
brasileira e nesse \\
campo os portugueses \\
avancaram muito.
\end{tabular}

Professor João José R. F. da Silva, a questão do plano de carreiras foi o tema mais discutido, "porque esta é a principal tarefa que nós temos agora, depois de o Presidente Sarney ter assinado os projetos-de-lei e os decretos que constituem a tarefa prioritária da Reforma Administrativa". Depois, explicou, passaremos ração das carreiras dos funcionários"'.

Aluizio Alves recordou, ainda, o que disse recentemente no programa Brasil-Entrevista da EBN: seu desejo é "criar um estado de espírito na sociedade, para que ela exija uma administração pública ágil, racional, competente. Nós vamos criar uma nova mentalidade do funcionatrabalho, uma tarefa nobre, uma tarefa da qual se orgulhe. Nós vamos procurar uma administração racional para um Pais que é um continente, onde os problemas $\mathrm{e}$ as soluções de Brasilia necessariamente nāo servem para as soluçōes dos problemas de Natal, nem de Belém, nem do Amapá". para a segunda fase, que é a prepalismo, estimulando-o a fazer, do seu 